\title{
Measuring Metacognitive Awareness: Applying Multiple, Triangulated, and Mixed-Methods Approaches for an Encompassing Measure of Metacognitive Awareness
}

\author{
Andrew J. Hughes
}

\begin{abstract}
The article provides an overview of the quantitative analysis of teachers' metacognitive awareness. The purpose of the overview is to express the need for encompassing measures of metacognition for improving metacognitive awareness in the field of technology and engineering education. The data presented come from using the Metacognitive Awareness Inventory to measure technology and engineering teachers' metacognitive awareness at the end of 2 specific professional development (PD) programs. The study had a sample size of 21. Participants were combined into 3 groups based on their participation in the PD programs. Group 1 consisted of teachers that actively participated in the Transforming Teaching through Implementing Inquiry (T2I2) PD program. Group 2 consisted of teachers that were selected for but did not actively participate in T2I2 PD program. Group 3 consisted of teachers that completed the National Board for Professional Teaching Standards PD program.
\end{abstract}

Keywords: Metacognition, metacognitive awareness, technology and engineering

Metacognitive awareness, the deliberate ability to explain one's knowledge and regulation of cognition, is woven into the philosophy of human experience. Surpassing lived (sensory) experience, we delve into cognizing related to lived experience, the apprehension of experience. "Any lived experience tends to evoke immediately a knowing of its characters ... and experiencer" (Spearman, 1923, p. 48). ${ }^{1}$ As with metacognition, not only can experiences be thought about but so can cognition itself.

I can know, not only that I know, but also what I know . ... Indeed, such a cognizing of cognition itself was already announced by Plato .... Aristotle likewise posited a separate power whereby, over and above actually seeing and hearing, the psyche becomes aware of doing so. (Spearman, 1923, p. 52)

\footnotetext{
${ }^{1}$ According to Spearman (1923), the term characters "includes all attributes that do not mediate between two or more fundaments. Its main divisions are quality and quantity" (p. 66).
} 
Aristotle's ideology on the mind's powers further established a foundation for metacognition as well as the mind's awareness of metacognition. Later philosophers, followers of Plato and Aristotle's doctrines including Strato, Galen, Alexander of Aphrodisias, and Plotinus, ranging from about 300 B.C. into late antiquity, continued to develop notions preceding the apperception of metacognition (Spearman, 1923; Georghiades, 2004).

Much later, educational psychologists including but not limited to Baldwin (1909), Binet (1909), Buhler (1907), Dewey (1910), Huey (1908), Locke (1924), and Thorndike (1914) continued to infer from observed phenomenon and advocate for cognitive knowledge and regulatory processes now considered component and subcomponents that constitute the psychological construct metacognition (as cited in Brown, 1987; see also, Georghiades, 2004). Jean Piaget's work on cognitive development psychology revealed that the stages of cognitive development were distinguishable, observable, and, with the proper method, measurable. Furthermore, "Piaget (1978) discussed the importance to human intelligence of the concept of reflected abstraction, with the result that cognitions be made stable and available to consciousness" (Campione, 1987, p. 120), "at which point they can be worked on and further extended (Campione 1987)" (Georghiades, 2004, p. 367).

Expanding on the work of Piaget, John Flavell (1976) was the first scholar to conceptualize the term metacognition. Flavell (1976) used the term metamemory to describe a person's knowledge of their own memory. Flavell (1976) also defined metacognition as "one's knowledge concerning one's own cognitive processes and products or anything related to them, e.g., the learningrelevant properties of information or data. For example, I am engaging in metacognition . . . if I notice that I am having more trouble learning $A$ than $B$; if it strikes me that I should double-check $C$ before accepting it as fact" (p. 232).

Succeeding Flavell's definition, the term metacognition has become ambiguous and is used synonymously to express several separate non-inclusive processes that are at best part of a metacognitive framework. The processes that underlie metacognition include but are not limited to: cognitive control, evaluating, goal setting, information management, judgments of learning, metalearning, metamentation, modeling, reflection, self-appraisal, selfmanagement, self-monitoring, self-reflection, self-regulation, and selfquestioning. As an example, the term reflection that is well represented in Locke (1924) and later Piaget's work is currently used in educational settings to circumscribe the process of being metacognitive. The variety of terms and definitions used in isolation yet equivalently associated with metacognition may be part of the reason that metacognition is considered ambiguous. "Flavell's definition was followed by numerous others, often portraying different emphases on (or different understanding of) mechanisms and processes associated with metacognition" (Georghiades, 2004, p. 365) and further contributing to the 
ambiguous nature of metacognition. The abstract, often unclear structure of metacognition makes measuring metacognition difficult and variable.

Measuring Metacognitive Awareness

Measuring metacognitive awareness entails utilizing metacognitive and research literature to develop a thorough understanding of metacognition, metacognitive processes and subprocesses, and research approaches. The research approach needs to allow for comprehensive data collection, analysis, and interpretation. Schraw $(2000,2009)$ and many others point out that no single research method or procedure of inquiry will allow for a complete understanding of a complex phenomenon like metacognitive awareness. For this reason, research using multiple, triangulated, and mixed-methods approaches is recommended (Pintrich, Wolters, \& Baxter, 2000; Schraw, 2000, 2009). In conjunction with research methods and procedures for inquiry, the research design also needs to include the researcher's analysis of philosophical assumptions and worldviews. The assumptions and worldviews should be explicitly stated because they can impact the researcher's approach, perception, and interpretation. The time required to conduct thorough metacognitive research often results in a research design with one method and one inquiry that measures metacognition superficially.

Researchers continue to use either quantitative or qualitative measures of metacognition awareness in isolation despite the trade-offs associated with individual metacognitive awareness measures. Schraw (2000) detailed six themes that emerged from the Buros Symposium. Theme four was "most available instruments that measure metacognition have unknown psychometric properties" (Schraw, 2000, p. 301). This fact creates two issues in the quantitative measurement of metacognition: (a) the instruments specific design and narrow usability and (b) the lack of background information development (Baker \& Cerro, 2000; Pintrich et al., 2000; as citied by Schraw, 2000). The Learning and Study Strategies Inventory (LASSI), Motivated Strategies for Learning Questionnaire (MSLQ), and Metacognitive Awareness Inventory (MAI) are three examples of quantitative self-reported measures that have psychometric reliability (Schraw, 2000). However, the LASSI and MSLQ only have metacognitive subscales and are more focused on learning strategies. A positive attribute of questionnaires is the ability to provide quick and objective measurement of metacognition, even with large sample sizes (Schellings \& Van Hout-Wolters, 2011). The negative aspect of questionnaires like the MAI relates to their validity (Harrison \& Vallin, 2018). It is worth noting that researchers like Harrison and Vallin (2018) are doing the quantitative metacognitive measurement analysis research suggest by Schraw (2000) and others.

Using qualitative measures provides a more complete, in-depth perception of metacognition when paired with other methods of inquiry. The use of interviews to provide depth to an investigation is a positive reason for 
including interviews in the research approach (Creswell, 2007; Denzin \& Lincoln, 1994). During an interview, the researcher can ask the participant to provide more detail about information that arises. This ability allows interviews to provide a more complete perspective of participant's metacognition in conjunction with quantitative measures. The required time for the participant and researcher to complete adequate length interviews is a major consideration when determining if interviews are appropriate. In addition to the time required for the interview, the time required to transcribe and code the interviews must also be considered (Creswell, 2007; Denzin \& Lincoln, 1994). Interviews are also a self-reported measurement, implying that the participant's honesty, reluctance to share, and ability to understand the questions may be an issue. Consequently, it is important for the researcher to create an environment that is comfortable for both the researcher and the participant (Denzin \& Lincoln, 1994).

Other qualitative objective behavior measures of metacognition include observations, think-aloud protocols, and performance evaluations. Think-aloud protocols are used so that the researcher can hear and see what the participant is doing during a task. There are two main problems with using a think-aloud protocol to measure metacognition (Scott, 2008). The first problem is that the participant may be more focused on thinking aloud rather than completing the cognitive task. The second problem relates to the functional use of think-aloud protocols. There is an appropriate time and place for think-aloud protocols (Scott, 2008). Group settings often make the use of think-aloud protocols inappropriate (Scott, 2008). In addition to think-aloud protocols, observations and performance evaluations also have trade-offs. Observations and performance evaluations can be used to determine participants' metacognitive actions. There may be a disconnect between apparent internal and external processes when using observations and performance evaluations. Additionally, like interviews, observations and performance evaluations are difficult and require time to implement and analyze even with a small number of participants.

\section{Background}

This study was purposefully conducted in conjunction with the research study presented in Hughes (2017). The combination of the data analyses in this study and in Hughes (2017) could aptly be considered a complementarity design. The overall purpose of the data collection, analysis, and interpretation presented in Hughes (2017) was to elaborate on the quantitative data collected and presented here. Other than complementarity, this design should also be considered convergent. As a convergent design, the analysis of the quantitative and qualitative data was performed separately. After the quantitative and qualitative data were analyzed separately, the data were then merged for comparative analysis to determine the convergence and divergence of metacognitive awareness components measured by the interview and MAI 
(Creswell, 2014). The design of the interview being based on the MAI provided a deeper, more complete understanding of the participants' metacognitive awareness.

In the study of a complex phenomenon, it is recommended that the researcher selects from multiple, triangulated, and mixed-methods approaches to offer thorough data collection for an encompassing measure. As stated above, the researcher's assumptions and subjectivity become essential for the reader's interpretation of results from the study. A reader should understand that the researcher is innate in the presentation of findings. As the researcher in this study, being objective may allow my subjectivity to comprehend metacognition as it exists. However, my subjectivity and assumptions may bias my perception of reality, making their analysis and presentation important. Subjectively, metacognition is extremely important for teachers and students' success, especially because of the complexity involved in teaching and learning science, technology, engineering, and mathematics disciplines. Furthermore, the assumption that metacognition is an important attribute for teachers or anyone dealing with high levels of complexity is based on being metacognitive during personal experiences involving complex thinking in relationship to engineering and teaching. This assumption leads to the belief that for technology and engineering teachers to adequately prepare students metacognitively for complex disciplines like engineering, they will need to develop more awareness of their own metacognition (Brophy, Klein, Portsmore, \& Rogers, 2008; Hughes, 2017).

This study involved two different professional development (PD) programs, Transforming Teaching through Implementing Inquiry (T2I2) and the National Board for Professional Teaching Standards (NBPTS). Although completion of either the T2I2 or the NBPTS programs involves metacognitive experiences, metacognitive development is not a primary focus of either PD program. Because of T2I2's connection with the NBPTS and its use of certain characteristics of $\mathrm{PD}$, the T2I2 program had a notable connection to metacognitive practices. T2I2 sought to promote technology and engineering teacher' attainment of national board certification by aligning with NBPTS. Based on the alignment between T2I2 and NBPTS, the guiding question of this study was: How do T2I2 participants' compare to nationally board certified technology and engineering teachers in terms of metacognitive awareness? This study was conducted over a 16-week period during fall 2014. After participants made an informed decision to participate, each was assigned a unique identifying number. The participant's MAI was encrypted with that number. The participants were sent the MAI in an email. Once all the MAIs were returned, the analysis of the data began by entering the participants' self-reported values on the MAI into the Statistical Package for the Social Sciences (SPSS). 


\section{Rationale}

Metacognitive research often focuses on students' thinking and regulation because of the belief that metacognitive awareness helps students to become better, more self-regulated learners (Harskamp \& Henry, 2009; Schwartz \& Perfect, 2002; Robson, 2006). Recently, metacognitive research has included a focus on teachers' metacognition corresponding with the belief that teachers lacking metacognitive awareness are unable to help students develop their metacognitive awareness (Harskamp \& Henry, 2009; Kramarski \& Michalsky, 2009; Prytula, 2012). Teacher PD has received attention as an available method to strengthen teachers' metacognitive awareness (Prytula, 2012; Wilson \& Conyers, 2016).

The literature indicates that measuring metacognitive awareness is difficult (Akturk \& Sahin, 2011; Harrison \& Vallin, 2018; Schraw, 2009). In designing this study, previous studies provided information on common methods for measuring metacognition. The literature comprising the foundation of these studies was used to evaluate the strengths and weaknesses of different methods in measuring metacognition. As metacognitive and research literature suggested for studying complex phenomenon, this study in conjunction with Hughes (2017) used two methods and procedures of inquiry. The use of the MAI in this study was also supported by the metacognitive and research literature. The Kruskal-Wallis one-way analysis of variance by ranks was used to compare grouped participant's metacognitive awareness. The Kruskal-Wallis test was selected based primarily on three reasons: (a) the ability to compare two or more independent groups, (b) the small sample size of this study resulting in nonnormally distributed data, and (c) the ranking of data to decrease impact of outliers (Sheskin, 2004). The Kruskal-Wallis is considered an extension of the Mann-Whitney U test but is designed to be used with two or more independent samples (Sheskin, 2004). The Kruskal-Wallis test operates under the assumptions of randomized selection of participants, group independence, continuous variable, and homogeneity of variance. When using a nonparametric statistic like the Kruskal-Wallis test, many researchers believe that there is an increased importance placed on validating the assumptions (Sheskin, 2004). Metacognitive awareness is not a continuous variable when using the MAI. The continuous variable assumption is frequently not adhered to during the KruskalWallis test with approval (Sheskin, 2004). Additionally, researchers commonly fail to check homogeneity of variance. There are several statistical tests that measure homogeneity of variance. Most commonly used with a Kruskal-Wallis test is a nonparametric Levene's test (Sheskin, 2004). The null hypothesis of the Kruskal-Wallis one-way analysis of variance by ranks is that the mean rank scores of Group 1 equal the mean rank scores of Group 2, which is continued for all $k$ groups (Sheskin, 2004).

To test homogeneity of variance in the context of the Kruskal-Wallis test, the nonparametric Levene's test was used. The two most common tests for 
homogeneity of variance are the Levene's test and the Brown-Forsythe test (Sheskin, 2004). The Levene and the Brown-Forsythe test would have similar results. The Brown-Forsythe test is sometimes selected because it is less impacted by the violation of the normality assumption (Sheskin, 2004). The nonparametric Levene's test compares the absolute difference of the ranked scores of each participant's metacognitive awareness and the mean of the rank scores. The nonparametric Levene's test is considered the most powerful and robust test for homogeneity of variance with non-normal distributed data (Nordstokke \& Zumbo, 2010).

\section{Instrumentation}

\section{Method}

In this study, the purpose of the MAI was to collect quantitative data on participants' current level of metacognitive awareness, knowledge of cognition, and regulation of cognition. The data were used to compare the three groups on their level of metacognitive awareness. Additionally, the groups were compared based on the knowledge and regulation of cognition components of metacognitive awareness. Schraw and Dennison (1994) indicated that the MAI provided a "reliable initial test of metacognitive awareness" when used with adults (p. 472). The MAI has been identified as the only currently available, reliable psychometric measure $(\alpha=.90$; Schraw and Dennison, 1994) that focuses on metacognitive awareness (Baker \& Cerro, 2000; Pucheu, 2008).

The MAI consists of two main components and eight subcomponents of metacognition, which are rated at five levels of awareness. Each one of the 52 questions align with one of the eight subcomponents. One main component from the MAI, Knowledge of Cognition, includes the following subcomponents and corresponding items from the MAI: Declarative Knowledge (Items 5, 10, 12, 16, 17, 20, 32, and 46), Procedural Knowledge (Items 3, 14, 27, and 33), and Conditional Knowledge (Items 15, 18, 26, 29, and 35). The other main component, Regulation of Cognition, includes the following components and items from the MAI: Planning (Items 4, 6, 8, 22, 23, 42, and 45), Organizing (Items 9, 13, 30, 31, 37, 39, 41, 43, 47, and 48), Monitoring (Items 1, 2, 11, 21, 28, 34, and 49), Debugging (Items 25, 40, 44, 51, and 52), and Evaluating (Items 7, 19, 24, 36, 38, and 50). The five levels of awareness are Always True (5), Sometimes True (4), Neutral (3), Sometimes False (2), and Always False (1).

\section{Participants}

Participants in this study were divided into the same three groups as presented in Hughes (2017): (Group 1) teachers who actively participated in and completed the T2I2 PD program; (Group 2) teachers who had been selected for but did not participate in the T2I2 program, completing less than $11 \%$ of the PD program; and (Group 3) teachers who had received National Board 
Certification (NBC) in CTE from the NBPTS. The participants were technology and engineering teachers from three states: Illinois, North Carolina, and Virginia. A combined total of 73 state-certified technology and engineering teachers were initially identified for possible participation in this study based on their involvement in one of the two PD programs. In an attempt to have equal group sizes and knowing the group with the least possible participants, 10 teachers from each group where randomly selected to participate. The 30 teachers received an email explaining the study and requesting their participation. A total of 21 teachers initially responded and completed the MAI, and a total of 18 teachers completed both the MAI and interview presented in Hughes (2017). Three participants only completed the MAI portion of the study with almost no demographic data collected, two females from Group 1 and one female from Group 3 (Table 1).

Table 1

Participant Group Demographics

\begin{tabular}{|c|c|c|c|c|c|c|c|}
\hline \multirow[b]{2}{*}{ Group } & \multicolumn{2}{|c|}{$\begin{array}{l}\text { Gender } \\
n(\%)\end{array}$} & \multicolumn{3}{|c|}{$\begin{array}{l}\text { Years of } \\
\text { Experience }\end{array}$} & \multicolumn{2}{|c|}{$\begin{array}{c}\text { Grade level taught } \\
n(\%)\end{array}$} \\
\hline & M & $\mathrm{F}$ & $n$ & Mean & $S D$ & $\begin{array}{l}\text { Middle } \\
\text { school }\end{array}$ & $\begin{array}{l}\text { High } \\
\text { school }\end{array}$ \\
\hline Group 1 & $\begin{array}{c}5 \\
(62.5 \%)\end{array}$ & $3(37.5 \%)$ & 6 & 20 & 11 & $3(50.0 \%)$ & $\begin{array}{c}3 \\
(50.0 \%)\end{array}$ \\
\hline Group 2 & $\begin{array}{c}4 \\
(66.7 \%)\end{array}$ & $2(33.3 \%)$ & 6 & 17.3 & 8.5 & $1(16.7 \%)$ & $\begin{array}{c}5 \\
(83.3 \%)\end{array}$ \\
\hline Group 3 & $\begin{array}{c}3 \\
(42.9 \%)\end{array}$ & $4(57.1 \%)$ & 6 & 21.5 & 8.2 & $3(50.0 \%)$ & $\begin{array}{c}3 \\
(50.0 \%)\end{array}$ \\
\hline Combined & $\begin{array}{c}12 \\
(57.1 \%)\end{array}$ & $9(42.9 \%)$ & 18 & 19.6 & 8.9 & $7(38.9 \%)$ & $\begin{array}{c}11 \\
(61.1 \%)\end{array}$ \\
\hline
\end{tabular}

\section{Comparing Participants}

The Kruskal-Wallis one-way analysis of variance by ranks was used to test if gender, teaching experience, path to certification, or grade level taught was resulting in a difference between participants metacognitive awareness based on their completion of the MAI. The first analysis compared the males' metacognitive awareness to the females' metacognitive awareness. The KruskalWallis test using gender as the independent variable resulted in a chi-square value of 2.79, 1 degree of freedom, and a $p$-value of .095 (Table 2). Based on these findings, the null hypothesis that males' metacognitive awareness equaled females' metacognitive awareness was supported. Next, the Kruskal-Wallis test 
was used to determine whether the participants' teaching experience impacted their metacognitive awareness. For this test, participants were compared in three reformed groups based on experience: (a) participants with 5 to 14, (b) 16 to 23, and (c) 27 to 34 years of teaching experience. The Kruskal-Wallis test using experience as the independent variable resulted in a chi-square value of .947, 2 degrees of freedom, and a $p$-value of .623 (Table 2). Based on these findings, the null hypothesis that groups based on years of experience are equal in terms of their metacognitive awareness was supported.

Then, the Kruskal-Wallis test was used to compare lateral-entry teachers' metacognitive awareness to traditionally certified teachers' metacognitive awareness. The Kruskal-Wallis test using certification path as the independent variable resulted in a chi-square value of $.316,1$ degree of freedom, and a $p$ value of .574 (Table 2). Based on these findings, the null hypothesis that lateral entry teachers' metacognitive awareness equaled traditionally certified teachers' metacognitive awareness was supported. Then, the Kruskal-Wallis test was used to compare middle school teachers' metacognitive awareness to high school teachers' metacognitive awareness. The Kruskal-Wallis test using grade level taught as the independent variable resulted in a chi-square value of $.461,1$ degree of freedom, and a $p$-value of .497 (Table 2). Based on these findings, the null hypothesis that middle school teachers' metacognitive awareness equals high school teachers' metacognitive awareness was supported.

\section{T2I2 Amount Completed}

The primary focus of this study was based on the premise that Groups 1 and 2 completed different amounts of PD in the T2I 2 program. Group 1 completed from $20 \%$ to $100 \%$ of T2I . It is also worth noting that the majority $(75 \%)$ of Group 1 participants completed $100 \%$ of T2I2. Group 2 had a range of T2I2 completed from $0 \%$ to $11 \%$. The majority ( $75 \%$ ) of Group 2 participants completed $5 \%$ or less of T2I 2 . The Kruskal-Wallis test was used to determine whether the difference in the amount of T2I 2 completed between Groups 1 and 2 was significant. The Kruskal-Wallis test using amount of T2I 2 completed as the independent variable resulted in a chi-square value of 10.4, 1 degree of freedom, and a $p$-value of .001 (Table 2). Based on these findings, the null hypothesis that the amount of T2I 2 completed by Group 1 equals the amount of T2I 2 completed by Group 2 was rejected. Group 3 was not involved with T2I 2 and therefore was not involved in this analysis. Additionally, for Group 3 participants to have NBC, they were required to complete $100 \%$ of the NBPTS PD. 
Table 2

Kruskal-Wallis Test Comparing Participants

\begin{tabular}{|c|c|c|c|c|c|}
\hline Variables & $n$ & Mean rank & Chi square & $d f$ & $p$ \\
\hline \multicolumn{6}{|l|}{ Gender } \\
\hline $\begin{array}{l}\text { Male } \\
\text { Female }\end{array}$ & $\begin{array}{c}12 \\
9\end{array}$ & $\begin{array}{c}13.81 \\
4.00\end{array}$ & 2.793 & 1 & .095 \\
\hline \multicolumn{6}{|l|}{ Experience (in years) } \\
\hline 5 to 14 & 6 & 8.00 & \multirow{3}{*}{.947} & \multirow{3}{*}{2} & \multirow{3}{*}{.623} \\
\hline 16 to 23 & 6 & 9.50 & & & \\
\hline 27 to 34 & 6 & 11.00 & & & \\
\hline \multicolumn{6}{|l|}{ Certification } \\
\hline $\begin{array}{l}\text { Traditional } \\
\text { Lateral }\end{array}$ & $\begin{array}{c}6 \\
12\end{array}$ & $\begin{array}{c}10.50 \\
9.00\end{array}$ & .316 & 1 & .574 \\
\hline \multicolumn{6}{|l|}{ Grade taught } \\
\hline $\begin{array}{l}\text { Middle } \\
\text { High }\end{array}$ & $\begin{array}{c}7 \\
11\end{array}$ & $\begin{array}{c}10.57 \\
8.82\end{array}$ & .461 & 1 & .497 \\
\hline \multicolumn{6}{|l|}{$\begin{array}{l}\text { Amount of T2I } 2 \\
\text { completed }\end{array}$} \\
\hline $\begin{array}{l}\text { Group } 1(20- \\
100 \%)\end{array}$ & 8 & 10.50 & \multirow[t]{2}{*}{10.40} & \multirow[t]{2}{*}{1} & \multirow[t]{2}{*}{.001} \\
\hline Group $2(0-11 \%)$ & 6 & 3.50 & & & \\
\hline
\end{tabular}

\section{Procedure}

The nonparametric Levene's test was used to validate the homogeneity of variance assumption (Sheskin, 2004). The null hypothesis of the nonparametric Levene's test is that the variances are equal. The nonparametric Levene's test resulted in an F-statistic of 2.249 and a $p$-value of .134. This indicated that the homogeneity assumption was valid for the metacognitive awareness data collected with the MAI.

Each group's level of metacognitive awareness was determined by the mean of responses to the 52 items by participants in that group. To determine each participant's awareness of their knowledge of cognition, the mean value was calculated based on the person's answers to the 17 items that corresponded with the knowledge component. The participant's awareness in the regulation of cognition component was the mean value of the other 35 items on the inventory that corresponded with the regulation component. The groups were compared on metacognitive awareness and its components using the Kruskal-Wallis test. 
The Kruskal-Wallis test was used to compare the groups on three items from the MAI, including: (a) metacognitive awareness, (b) knowledge of cognition, and (c) regulation of cognition. The Kruskal-Wallis test was used four times for the different group combinations: Groups 1, 2, and 3 (Table 3); Groups 1 and 2 (Table 4); Groups 2 and 3 (Table 5); and Groups 1 and 3 (Table 6).

Using SPSS to calculate Kruskal-Wallis produced a chi-square value that could be used to calculate an effect-size estimate known as eta squared. The effect-size estimate determined the percent of variability in the rank scores from the Kruskal-Wallis test, and it accounted for differences in the teachers' metacognitive awareness based on their participation in PD. In this study, the effect size was used to represent the strength of the relationship between the independent and dependent variables.

\section{Results}

Table 3 shows the results of the omnibus Kruskal-Wallis analysis, which included all three groups. In this case, the Kruskal-Wallis test looked for any difference in the three components among the three groups. Table 3 displays the mean rank scores for each group in each component. Group 2 had the lowest mean rank score in each component. In Table 3 , the significance column illustrates that all three of the components were statistically significant at an alpha level of .05. In this test, the analysis did not indicate which group was different from another group. Later tests directly compared one group to another group. Also shown in Table 3 is the eta-squared value for each component. Eta squared quantifies the amount that the groups differed for each component. In Table 3 , the eta-squared value for metacognitive awareness was .535, signifying that $53.5 \%$ of the variability in the rank scores for metacognitive awareness was accounted for based on the groups' participation in PD. 
Table 3

Kruskal-Wallis Test for Metacognitive Awareness All Three Groups

\begin{tabular}{lcccccc}
\hline \multicolumn{1}{c}{ Component } & Group & $n$ & $\begin{array}{c}\text { Mean } \\
\text { rank }\end{array}$ & $\begin{array}{c}\text { Chi } \\
\text { square }\end{array}$ & $\begin{array}{c}\text { Eta } \\
\text { squared }\end{array}$ & $p$ \\
\hline $\begin{array}{l}\text { Metacognitive } \\
\text { awareness }\end{array}$ & 1 & 8 & 13.81 & & & \\
& 2 & 6 & 4.00 & 10.705 & .535 & .005 \\
& 3 & 7 & 13.79 & & & \\
$\begin{array}{l}\text { Regulation of } \\
\text { cognition }\end{array}$ & 1 & 8 & 13.63 & & & \\
& 2 & 6 & 3.83 & 11.239 & .562 & .004 \\
$\begin{array}{l}\text { Knowledge of } \\
\text { cognition }\end{array}$ & 3 & 7 & 14.14 & & & \\
& 1 & 8 & 13.50 & & & \\
& 2 & 6 & 5.67 & 6.299 & .315 & .043 \\
& 3 & 7 & 12.71 & & & \\
\hline
\end{tabular}

Table 4 shows a direct comparison between Groups 1 and 2 using the Kruskal-Wallis test. In this case, the Kruskal-Wallis looked for a difference in the three components between Groups 1 and 2. Group 2 again had the lower mean rank score in all three components. The results of the Kruskal-Wallis test comparing Groups 1 and 2 indicated that Group 1 had a higher level of metacognitive awareness.

Table 4

Kruskal-Wallis Test for Metacognitive Awareness Groups 1 and 2

\begin{tabular}{lcccccc}
\multicolumn{1}{c}{ Component } & Group & $n$ & $\begin{array}{c}\text { Mean } \\
\text { rank }\end{array}$ & $\begin{array}{c}\text { Chi } \\
\text { square }\end{array}$ & $\begin{array}{c}\text { Eta } \\
\text { squared }\end{array}$ & $p$ \\
\hline $\begin{array}{l}\text { Metacognitive } \\
\text { awareness }\end{array}$ & 1 & 8 & 10.38 & 8.817 & .678 & .003 \\
$\begin{array}{l}\text { Regulation of } \\
\text { cognition }\end{array}$ & 1 & 6 & 3.67 & & & \\
$\begin{array}{l}\text { Knowledge of } \\
\text { cognition }\end{array}$ & 2 & 6 & 3.67 & 8.836 & .680 & .003 \\
\hline
\end{tabular}

Table 5 shows a comparison between Groups 2 and 3 using the KruskalWallis test. The results of this test were not unlike the comparison of Groups 1 
and 2 because Groups 1 and 3 had similar mean rank scores and Group 2 had the lowest mean rank scores. The Kruskal-Wallis was again testing to determine whether the differences in mean rank scores was significant between Groups 2 and 3. The results of the Kruskal-Wallis test comparing Groups 2 and 3 indicated that Group 3 had a higher level of metacognitive awareness with a chisquare value of 7.388, 1 degree of freedom, and a $p$-value of .007 (Table 5).

Table 5

Kruskal-Wallis Test for Metacognitive Awareness Groups 2 and 3

\begin{tabular}{lcccccc}
\hline \multicolumn{1}{c}{ Component } & Group & $n$ & $\begin{array}{c}\text { Mean } \\
\text { rank }\end{array}$ & $\begin{array}{c}\text { Chi } \\
\text { square }\end{array}$ & $\begin{array}{c}\text { Eta } \\
\text { squared }\end{array}$ & $p$ \\
\hline $\begin{array}{l}\text { Metacognitive } \\
\text { awareness }\end{array}$ & 2 & 6 & 3.83 & 7.388 & .616 & .007 \\
& 3 & 7 & 9.71 & & & \\
$\begin{array}{l}\text { Regulation of } \\
\text { cognition }\end{array}$ & 2 & 6 & 3.67 & 8.186 & .682 & .004 \\
& 3 & 7 & 9.86 & & & \\
$\begin{array}{l}\text { Knowledge of } \\
\text { cognition }\end{array}$ & 2 & 6 & 4.58 & 4.315 & .360 & .038 \\
\hline
\end{tabular}

The previous Kruskal-Wallis tests showed that Groups 1 and 3 had a higher level of metacognitive awareness than Group 2 based on the data from the MAI. Table 6 shows a comparison between Groups 1 and 3 using the Kruskal-Wallis test. In Table 6, the significance column shows that all three components were above the alpha of .05. This use of the Kruskal-Wallis tested the null hypothesis that Group 1's metacognitive awareness was equal to Group 3's metacognitive awareness. Based on the $p$-values in Table 6, Group 1's metacognitive awareness was similar to Group 3's metacognitive awareness. In fact, metacognitive awareness had a chi-square value of $.003,1$ degree of freedom, and a $p$-value of .954, indicating a significant similarity. 
Table 6

Kruskal-Wallis Test for Metacognitive Awareness Groups 1 and 3

\begin{tabular}{lcccccc}
\hline \multicolumn{1}{c}{ Component } & Group & $n$ & $\begin{array}{c}\text { Mean } \\
\text { rank }\end{array}$ & $\begin{array}{c}\text { Chi } \\
\text { square }\end{array}$ & $\begin{array}{c}\text { Eta } \\
\text { squared }\end{array}$ & $p$ \\
\hline $\begin{array}{l}\text { Metacognitive } \\
\text { awareness }\end{array}$ & 1 & 8 & 7.94 & .003 & .000 & .954 \\
$\begin{array}{l}\text { Regulation of } \\
\text { cognition }\end{array}$ & 3 & 7 & 8.07 & & & \\
$\begin{array}{l}\text { Knowledge of } \\
\text { cognition }\end{array}$ & 1 & 8 & 7.75 & .054 & .004 & .817 \\
\hline
\end{tabular}

\section{Implications}

The findings of this research in relation with the findings presented in Hughes (2017) relate to metacognitive research design; PD effectiveness, design, and focus; and teachers in general. However, the technology and engineering education field might find the results presented here and in Hughes (2017) of particular interest. Knowing how to measure and ensure positive influence on metacognitive awareness will benefit both students and teachers in the technology and engineering education field. Technology and engineering teachers focus on hands-on learning and associated thinking; integrally applying science and mathematics to solve ill-structured open-ended problems; and numerous other complex concepts including design, modeling, systems, and creativity inflating the need for metacognitive awareness (Brophy et al., 2008). Brophy, Klein, Portsmore, and Rogers (2008) do not explicitly state metacognitive awareness as a need but do reference content and cognitive knowledge and regulation (control) components of metacognitive awareness as key to advancing the teaching and learning of engineering. Remembering that when the technology and engineering education field discusses higher order thinking, systems thinking, critical thinking, cognitive processes, aspects of cognitive control (e.g., reflection), and other intrinsically cognitive activities, the field is referencing processes that are and should be considered part of a metacognitive framework.

The first finding from this study indicated that Groups 1 and 3 had similar levels in metacognitive awareness, knowledge of cognition, and regulation of cognition components. The metacognitive awareness interview results presented in Hughes (2017) converged with this finding of the MAI data analysis. Overall, based on the MAI and interview results, Groups 1 and 3 had similar levels of metacognitive awareness, knowledge of cognition, and regulation of cognition. The second finding indicated that Groups 1 and 3 had higher levels of 
metacognitive awareness, knowledge of cognition, and regulation of cognition when compared with Group 2. Hughes (2017) implies that each group's metacognitive awareness could indicate their likelihood to successfully complete PD, especially self-regulated PD programs like T2I2 and NBPTS. The interview results converged with MAI results that Groups 1 and 3 had higher levels than Group 2 in metacognitive awareness and regulation of cognition but diverged on the knowledge of cognition component (Hughes, 2017). The MAI results indicated that Groups 1 and 3 had higher levels in the knowledge of cognition component. Based on the interview results, all three groups had similar, medium to low, levels of knowledge of cognition (Hughes, 2017). The MAI and interview data also diverged in another area. The MAI and interview results suggested a difference between the groups on the regulation of cognition component. However, the MAI data only indicated a difference, whereas the interview data expressed unique differences.

The similarities and differences in the MAI and interview data support that no single research method or procedure of inquiry will allow for a complete understanding of a complex phenomenon like metacognitive awareness. Additionally, the uniqueness of each group's metacognitive awareness, especially in the regulation of cognition component, seen during the interview data analysis further supports that no single method will provide a thorough understanding of metacognitive awareness. The uniqueness of each group's metacognitive awareness seen in the interview results further supports the ambiguity of metacognition (Hughes, 2017). There is no single word or process that would adequately describe each group's metacognition. Metacognition encompasses several components, subcomponents, and processes that function together in varying combinations. The uniqueness of each group's metacognition further supports the importance for the researcher to have an informed understanding of metacognition. Metacognition is complex because it characterizes a multitude of cognitive as well as noncognitive processes.

Metacognition has surpassed its philosophical acknowledgement by becoming a mainstay in educational psychology, teacher preparation, teacher PD, and modern classrooms. As technology and engineering education continues to include increasingly complex connections between thinking and doing, teachers' and students' metacognitive awareness will remain important for teaching and learning.

\section{Conclusions}

The intent of this article was to acknowledge the complexity of metacognition, demonstrating that metacognition should be measured using more than one method and procedure of inquiry for encompassing results. The intent of the data collection presented here was to provide an initial measure of metacognition awareness for each group of participants to compare their level of metacognitive awareness. Prior to collecting data, it was believed that successful PD completers would have higher levels of metacognitive awareness, knowledge 
of cognition, and regulation of cognition. Based on the MAI data presented in this article, that would appear to be the case. However, when the MAI data are compared with the interview data from Hughes (2017), there is convergence and divergence between both data analyses. The significant differences seen in the knowledge of cognition component of the quantitative data were not paralleled by the results of the qualitative data. The qualitative data suggested similarity between groups in the knowledge of cognition component (Hughes, 2017). The significant differences from the quantitative data in regulation of cognition were represented as more of uniqueness differences in the regulation of cognition subcomponents between groups in the qualitative data (Hughes, 2017).

Technology and engineering teachers engage students in ill-structured, open-ended problem-solving and design activities integrating science, technology, engineering, and mathematics content requiring thoughtful teacher practices. The complex thinking involved with the interdisciplinary approach of content and pedagogical knowledge required for technology and engineering education requires teachers to cognitively prepare, monitor, adapt, and reflect (Barak, 2010; Kramarski \& Michalsky, 2009; Lin, Schwartz, \& Hatano, 2005). Metacognitive awareness expressed by content and cognitive knowledge and regulation components from the technology and engineering education field implies the importance of metacognitive awareness development (Barak, 2010; Hughes, 2017; Petrina, Feng, \& Kim, 2008). This article is applicable to future work in measuring complex phenomenon like metacognitive awareness and the approach to studying metacognition.

\section{References}

Akturk, A. O., \& Sahin, I. (2011). Literature review on metacognition and its measurement. Procedia - Social and Behavioral Sciences, 15, 3731-3736. doi:10.1016/j.sbspro.2011.04.364

Baker, L., \& Cerro, L. C., (2000). Assessing metacognition in children and adults. In G. Schraw \& J. C. Impara (Eds.), Issues in the measurement of metacognition (pp. 99-145). Lincoln: Buros Institute of Mental Measurements, University of Nebraska-Lincoln.

Barak, M. (2010). Motivating self-regulated learning in technology education. International Journal of Technology and Design Education, 20(4), 381401. doi:10.1007/s10798-009-9092-x

Brophy, S., Klein, S., Portsmore, M., \& Rogers, C. (2008). Advancing engineering education in P-12 classrooms. Journal of Engineering Education, 97(3), 369-387. doi:10.1002/j.2168-9830.2008.tb00985.x

Brown, A. (1987). Metacognition, executive control, self-regulation, and other more mysterious mechanisms. In F. E. Weinert \& R. H. Kluwe (Eds.), Metacognition, motivation and understanding (pp. 65-116). Hillsdale, NJ: Erlbaum. 
Campione, J. C. (1987). Metacognitive components of instructional research with problem learners. In F. E. Weinert \& R. H. Kluwe (Eds.), Metacognition, motivation, and understanding (pp. 117-140). Hillsdale, NJ: Erlbaum.

Creswell, J. W. (2007). Qualitative inquiry \& research design: Choosing among five approaches (2nd ed.). Thousand Oaks, CA: Sage.

Creswell, J. W. (2014). Research design: Qualitative, quantitative, and mixed methods approaches (4th ed.). Thousand Oaks, CA: Sage

Denzin, N. K., \& Lincoln, Y. S. (1994). Handbook of qualitative research. Thousand Oaks, CA: Sage.

Flavell, J. H. (1976). Metacognitive aspects of problem solving. In L. B. Resnick (Ed.), The nature of intelligence (pp. 231-235). Hillsdale, N J: Erlbaum.

Georghiades, P. (2004). From the general to the situated: Three decades of metacognition. International Journal of Science Education, 26(3), 365-383. doi:10.1080/0950069032000119401

Harrison, G. M., \& Vallin, L. M. (2018). Evaluating the Metacognitive Awareness Inventory using empirical factor-structure evidence. Metacognition and Learning, 13(1), 15-38. doi:10.1007/s11409-017-9176-z

Harskamp, E. G., \& Henry, D. (2009). Introduction to this special issue. Educational Research and Evaluation, 15(5), 429-433. doi:10.1080/13803610903444469

Hughes, A. J. (2017). Educational complexity and professional development: Teachers' need for metacognitive awareness. Journal of Technology Education, 29(1), 25-44. doi:10.21061/jte.v29i1.a.2

Kramarski, B., \& Michalsky, T. (2009). Investigating preservice teachers' professional growth in self-regulated learning environments. Journal of Educational Psychology, 101(1), 161-175. doi:10.1037/a0013101

Lin, X., Schwartz, D. L., \& Hatano, G. (2005). Toward teachers' adaptive metacognition. Educational Psychologist, 40(4), 245-255. doi:10.1207/s15326985ep4004_6

Locke, J. (1924). An essay concerning human understanding (A. L. PringlePattison, Ed.). Oxford, England: Clarendon Press.

Nordstokke, D. W., \& Zumbo, B. D. (2010). A new nonparametric Levene test for equal variances. Psicológica, 31(2), 401-430. Retrieved from https://www.uv.es/psicologica/articulos2.10/11NORDSTOKKE.pdf

Petrina, S., Feng, F., \& Kim, J. (2008). Researching cognition and technology: How we learn across the lifespan. International Journal of Technology and Design Education, 18(4), 375-396. doi:10.1007/s10798-007-9033-5

Pintrich, P. R., Wolters, C. A., \& Baxter, G. P. (2000). Assessing metacognition and self-regulated learning. In G. Schraw \& J. C. Impara (Eds.), Issues in the measurement of metacognition (pp. 43-97). Lincoln: Buros Institute of Mental Measurements, University of Nebraska-Lincoln. 
Prytula, M. P. (2012). Teacher metacognition within the professional learning community. International Education Studies, 5(4), 112-121. doi:10.5539/ies.v5n4p112

Pucheu, P. M. (2008). An investigation of the relationships between the Scoring Rubrics Inventory and the Metacognitive Awareness Inventory as reported by secondary school core-subject teachers (Doctoral dissertation). Available from ProQuest Dissertations and Theses database. (UMI No. 3313868)

Robson, J. (2006). Teacher professionalism in further and higher education: Challenges to culture and practice. Abingdon, England: Routledge. doi:10.4324/9780203397299

Schellings, G., \& Van Hout-Wolters, B. (2011). Measuring strategy use with self-report instruments: Theoretical and empirical considerations. Metacognition and Learning, 6(2), 83-90. doi:10.1007/s11409-011-9081-9

Schraw, G. (2000). Assessing metacognition: Implications of the Buros Symposium. In G. Schraw \& J. C. Impara (Eds.), Issues in the measurement of metacognition (pp. 297-321). Lincoln: Buros Institute of Mental Measurements, University of Nebraska-Lincoln.

Schraw, G. (2009). A conceptual analysis of five measures of metacognitive monitoring. Metacognition and Learning, 4(1), 33-45. doi:10.1007/s11409008-9031-3

Schraw, G., \& Dennison, R. S. (1994). Assessing metacognitive awareness. Contemporary Education Psychology, 19(4), 460-475. doi:10.1006/ceps.1994.1033

Schwartz, B. L., \& Perfect, T. J. (2002). Introduction: Toward an applied metacognition. In T. J. Perfect \& B. L. Schwartz (Eds.), Applied metacognition (pp. 1-11). Cambridge, England: Cambridge University Press. doi:10.1017/CBO9780511489976.002

Scott, B. M. (2008). Exploring the effects of student perceptions of metacognition across academic domains (Doctoral dissertation). Available from ProQuest Dissertations and Theses database. (UMI No. 3331280)

Sheskin, D. J. (2004). Handbook of parametric and non-parametric statistical procedures (3rd ed.). Boca Raton, FL: Chapman \& Hall/CRC. doi:10.4324/9780203489536

Spearman, C. (1923). The nature of "intelligence" and the principles of cognition. Oxford, England: Macmillan.

Wilson, D., \& Conyers, M. (2016). Teaching students to drive their brains: Metacognitive strategies, activities, and lesson ideas. Alexandria, VA: ASCD.

\section{About the Author}

Andrew J. Hughes (andrew.hughes@csusb.edu) is Assistant Professor in the Career and Technical Education Program at California State University San Bernardino. 